\title{
Overexpression of HOP2 induces developmental defects and compromises growth in Arabidopsis
}

Ameth N. Garrido, Therese Francom, Sakina Divan, Mohamad Kesserwan, Jenya Daradur, and C. Daniel Riggs

Department of Biological Sciences

University of Toronto, Scarborough

1265 Military Trail

Toronto, ON. M1C1A4

corresponding author email: dan.riggs@utoronto.ca

key words: HOP2/development/fecundity/floral mutant/meiosis 


\begin{abstract}
HOMOLOGOUS PAIRING 2 (HOP2) is a predominantly meiotic protein that plays a pivotal role in homologous chromosome pairing in organisms as diverse as yeast and mammals. While generating HOP2::GFP reporter lines, we identified two Arabidopsis T-DNA insertion mutants, stunted1 (std1) and stunted2 (std2) that exhibit pleiotropic phenotypes, including fasciated stems, altered phyllotaxy, floral organ defects, reduced fecundity, and an overall reduction in growth properties. TAIL-PCR followed by sequencing revealed several insertions near genes, but genotyping showed that none of the insertions are causal. Analysis the std mutants by qRT$\mathrm{PCR}$, and analysis of dexamethasone inducible HOP2 transgenic plants demonstrated that the std phenotypes are associated with ectopic/overexpression of HOP2. Based on the postulated mechanisms of HOP2 action, we speculate on how overexpression leads to these developmental/growth defects.
\end{abstract}

\title{
Introduction
}

Meiosis is an evolutionarily conserved cell division mechanism that generates genetic diversity in the meiotic products, either gametes or spores, depending on the organism. After cells are committed to meiosis, the duplicated chromosomes undergo intricate movements and interactions that promote the alignment of homologous pairs, which subsequently exchange segments during recombination. These movements may involve the attachment of telomeres to either the nuclear membrane or the nucleolus, the clustering of centromeres, and the synapsis of the chromosome arms (Unhavaithaya and Orr-Weaver, 2013; Da Ines and White, 2015; Hurel et al., 2018; Sepsi and Schwarzacher, 2020; Tian et al., 2020). As synapsis proceeds, a proteinaceous matrix, the synaptonemal complex (SC) is assembled between the paired homologs and commitment to crossing over occurs. Double strand breaks (DSBs) are induced during meiosis and they are repaired using Homologous Recombination repair (HR). Many eukaryotes, including Arabidopsis, rely on HR repair of DSBs to accomplish both synapsis and crossing over. In most organisms the concerted action of numerous proteins, including RAD51, DMC1, MND1 and HOP2 are required for these processes (reviewed by Ranjha et al., 2018; Crickard and Greene, 2018). RAD51 and DMC1 are both RecA type recombinases that promote the formation of the ssDNA nucleofilaments that invade dsDNA and initiate strand exchange that can lead to a crossover. HOP2 and MND1 are accessory proteins that form a heterodimer, and are proposed to tether the ssDNA to dsDNA, providing a critical level of stabilization. In yeast and mammals, null mutations in HOP2 or MND1 lead to a general failure in homologous chromosome SC formation and repair of DSBs, resulting in meiotic arrest (Leu et al., 1998; Tsubouchi and Roeder, 2003; Petukova et al. 2003). In Arabidopsis and rice, HOP2 and MND1 null mutants also have a general failure of SC formation, but DSBs are repaired and there is no meiotic arrest (Kerzendorfer et al., 2006; Panoli et al., 2006; Stronghill et al., 2010, Shi et al., 2019). Despite the general lack of SC formation in Arabidopsis hop2 or mnd1 mutants, aberrant chromosome segregation with chromatin bridges and fragments was observed, suggesting that HOP2 and/or MND1 have a dual role both in promoting SC formation between homologs or preventing stable associations from forming between nonhomologous chromosomes (Farahani-Tafreshi et al., 2021). Mechanistically, HOP2 and MND1's action is not completely understood, but in vitro studies provide evidence that the HOP2/MND1 heterodimer modulates the activity of the RAD51 and DMC1 recombinases and HOP2, in the 
absence of MND1 is a potent recombinase (Petukova et al., 2005; Neale and Keeney 2006; Ploquin et al., 2007; Bugreev et al., 2014; Tsubouchi et al., 2020).

To support our on-going work on Arabidopsis HOP2, we attempted to generate a reporter gene transgenic lines by linking the HOP2 promoter and coding region to a construct encoding the fluorescent reporter GFP. We were successful in generating reporter lines, which had a normal meiosis and expressed GFP in the meiotic cells, but we also observed some transformants that displayed a range of developmental abnormalities. Here we report the characterization of two such mutants that we termed stunted1 (std1) and stunted2 (std2). We propose that ectopic/overexpression of HOP2 is responsible for the std phenotypes.

\section{Experimental Procedures}

The hop2-1 mutant was obtained from the Arabidopsis Biological Resource Center (ABRC). Plants were grown in Conviron growth chambers on a $16 \mathrm{hr}$ day/8hr night regimen under fluorescent lights $\left(\sim 125 \mu \mathrm{E} / \mathrm{m}^{2}\right)$ in Premier Promix PGX medium.

\section{Generation of std mutants}

PCR was used to amplify the wildtype HOP2 gene to generate a construct containing $4681 \mathrm{bp}$ preceding the start codon, and creating an in-frame fusion with the coding region of GFP in a pEGAD derivative. Primer sequences and the construction strategy are given in Table S1. DNA sequencing confirmed the translational in-frame fusion. Agrobacterium mediated transformation of either Columbia or Landsberg erecta (Ler) plants was employed and transformants selected by growth on $0.5 \mathrm{X}$ MS plates containing $10 \mathrm{ug} / \mathrm{ml}$ BASTA.

\section{Microscopy}

Light microscopy and image capture were undertaken by using a Leica MZ 7.5 or Nikon SMZ1500 dissecting microscopes. For scanning electron microscopy, samples were prepared and examined by employing a Hitachi S-530 scanning electron microscope at $25 \mathrm{kV}$, as described by Douglas et al. (2002), and images were captured using the Quartz PCI version 8 system.

\section{TAIL-PCR}

Genomic DNA from std1 and std2 mutants was prepared and used in TAIL-PCR essentially as described by Sessions and coworkers (2002). Two rounds of amplification were conducted using New England Biolabs Q5 polymerase. In the primary reactions a T-DNA border primer was used with a combination of degenerate primers (see Table S1), and PCR parameters were as follows: $94^{\circ} \mathrm{C}, 2 \mathrm{~min} ; 5$ cycles of $98^{\circ} \mathrm{C}, 15 \mathrm{sec} / 62^{\circ} \mathrm{C}, 60 \mathrm{sec} / 72^{\circ} \mathrm{C}, 120 \mathrm{sec}$; then 2 cycles of $98^{\circ} \mathrm{C}, 15 \mathrm{sec} / 25^{\circ} \mathrm{C}, 180 \mathrm{sec}$, with ramp rate $0.5^{\circ} \mathrm{C}$ per sec $/ 72^{\circ} \mathrm{C}, 120 \mathrm{sec}$; then $15 \mathrm{cycles}$ of $98^{\circ} \mathrm{C}, 15 \mathrm{sec} / 68^{\circ} \mathrm{C}, 60 \mathrm{sec} / 72^{\circ} \mathrm{C}, 120 \mathrm{sec} / 98^{\circ} \mathrm{C}, 15 \mathrm{sec} / 68^{\circ} \mathrm{C}, 60 \mathrm{sec} / 72^{\circ} \mathrm{C}, 120 \mathrm{sec} / 98^{\circ} \mathrm{C}, 20$ $\mathrm{sec} / 44^{\circ} \mathrm{C}, 60 \mathrm{sec} / 72^{\circ} \mathrm{C}, 120 \mathrm{sec} / 72^{\circ} \mathrm{C}, 180 \mathrm{sec}$. One microliter of the primary reaction was used in secondary reactions with parameters: $94^{\circ} \mathrm{C}, 2.5 \mathrm{~min} ; 5$ cycles of $98^{\circ} \mathrm{C}, 20 \mathrm{sec} / 62^{\circ} \mathrm{C}, 60$ $\mathrm{sec} / 72^{\circ} \mathrm{C}, 120 \mathrm{sec}$; then $15 \mathrm{cycles}$ of $98^{\circ} \mathrm{C}, 15 \mathrm{sec} / 64^{\circ} \mathrm{C}, 60 \mathrm{sec} / 72^{\circ} \mathrm{C}, 120 \mathrm{sec} / 98^{\circ} \mathrm{C}, 15$ $\mathrm{sec} / 64^{\circ} \mathrm{C}, 60 \mathrm{sec} / 72^{\circ} \mathrm{C}, 120 \mathrm{sec} / 98^{\circ} \mathrm{C}, 20 \mathrm{sec} / 44^{\circ} \mathrm{C}, 60 \mathrm{sec} / 72^{\circ} \mathrm{C}, 120 \mathrm{sec}$, then 5 cycles of $98^{\circ} \mathrm{C}$, $20 \mathrm{sec} / 44^{\circ} \mathrm{C}, 60 \mathrm{sec} / 72^{\circ} \mathrm{C}, 120 \mathrm{sec} /$, then $72^{\circ} \mathrm{C}, 180 \mathrm{sec}$. The reactions were subjected to agarose gel electrophoresis and DNA fragments visualized by staining with Red-Safe (Frogga 
Bio). The bands were resected and purified by employing a Bio-Basic ez10 gel purification kit. The purified DNA was then sequenced with the T-DNA border primer at the Hospital for Sick Children TCAG facility (Toronto).

\section{T-DNA insertion analysis}

The status of T-DNA insertions into loci defined by TAIL-PCR sequencing was undertaken by the standard method of employing two PCR reactions. To test for an uninterrupted (wildtype) gene, primers that flank the T-DNA insertion site were used; to test for a T-DNA insertion, a gene specific primer/T-DNA border primer was employed. To examine the organization of the T-DNA insertions as tandem repeats, convergent or divergent insertions, we employed the relevant T-DNA border primers from one or both ends (see Table S1 for primers and strategy).

\section{$D E X$-inducibility construct and DEX assays}

We generated a DEX inducible HOP2 construct by amplifying the HOP2 gene with primers that added attB sites (see Table S1), then mobilized the clone into pDONR207 by employing Gateway technology (Invitrogen) to generate an entry clone. The sequence was then inserted into pDEX to generate the destination clone that contains a C-terminal HA tag in frame with HOP2 (construct LC842). LC842 was mobilized into Agrobacterium GV3101 and used to transform Ler plants by the floral dip method. Transgenic plants were selected on medium containing $0.5 \mathrm{X}$ MS salts, $5 \mathrm{mM}$ MES, pH5.7, $1 \%$ sucrose, $0.8 \%$ agar, and $10 \mathrm{ug} / \mathrm{ml}$ BASTA.

For plate assays, LC842 and Ler seeds were surface sterilized and germinated on either MS medium (Ler) or MS medium containing BASTA (LC842), as outlined above. After 3 days of stratification at $4^{\circ} \mathrm{C}$, plates were moved to room temperature under fluorescent lighting and allowed to grow for one week, then transferred to either control plates (MS medium) or MS plates containing 1uM dexamethasone (BioShop). Plates were imaged on day 0 (day of transfer) and day 5. For qRT-PCR experiments, seedlings were collected after 3 days and used to prepare RNA for analysis of transcript levels.

For in terra analyses, Ler and LC842 seedlings were transferred from plates into pots containing Promix. Each 4-inch pot contained one seedling of each genotype. Control pots were spritzed with water containing $0.05 \%$ silwet, and DEX treatment was conducted by spritzing experimental pots with the same solution containing $1 \mathrm{mM}$ dexamethasone. Inflorescences were thoroughly wetted and spritzing was repeated every other day, for a total of four times. Plants were then imaged to capture phenotypic changes induced by DEX.

qRT-PCR

RNA from plant tissues was purified and qRT-PCR conducted as described by Douglas et al., 2017. Primer and amplicon details are given in Table S1.

\section{Results}

In the process of generating reporter lines to monitor HOP2 expression, we identified a transformant that exhibited a variety of developmental abnormalities. At maturity, the plant was much shorter than wildtype and possessed thicker epinastic leaves, as well as thick and often fasciated stems (Figure 1). We also observed numerous instances of phyllotaxy defects, elevated levels of anthocyanins, and some instances of fused organs. Reproductive 
development was severely compromised. Floral buds appeared somewhat flattened and growth patterns of all organs were affected. Sepals and petals were shorter than wildtype and failed to enclose the reproductive whorls, creating an open flower phenotype. Stamens were disproportionally short and produced little or no pollen. The gynoecium was often open at the stigma and in some cases the carpels had failed to fuse. In general, very few stigmatic papillae were produced and fecundity was severely reduced. Given the overall slow growth and organ defects, we elected to call this mutant stunted (std). Occasionally the more normal looking pistils could be successfully fertilized with wildtype pollen and three general phenotypic classes were observed in the F2 progeny (Figure S1). The first class was nearly wildtype, but there were occasional minor phyllotaxy defects and fecundity issues. The second class of segregants was shorter than those of class 1 and exhibited more extreme phenotypes, being overall very similar to the original std mutant. Class 3 segregants were severely stunted and the phenotypic defects observed in the original std mutant were exacerbated. Overall, there was broad range of defects that were sometimes not shared and the segregation ratio for the three classes was $2: 2: 1$, which does not correspond to Mendelian ratios that point to recognized modes of inheritance.

The stunted mutant is unlikely due to T-DNA insertion into a developmental regulatory gene We hypothesized that std1 arose due to random insertion of the reporter gene T-DNA into an important regulatory gene. To identify the insertion site, we performed thermal asymmetric interlaced PCR (TAIL-PCR) followed by sequencing of the products. In total, 38 sequences were obtained. About half of these sequences were revealed to be complex T-DNA rearrangements, head to tail tandem repeats of T-DNA, or were read-through sequences extending beyond the T-DNA left border sequence (Table 1). Sequence analysis of the transforming construct as well as the read-through insertions revealed no mutations within the LB and RB border sequences, and thus the mechanism(s) that produced these aberrant events is unknown, but the observations are not unprecedented (De Buck et al., 1999; De Neve et al., 1997; Wei et al., 2015). Amongst the TAIL-PCR sequences we found multiple hits for insertions in or near four genes: At4g16490, At3g21790, At3g47580, and At3g03460. In the first three cases, insertion occurred in the proximal promoter region of the genes and in the case of At3g03460, the insertion was $600 \mathrm{bp}$ downstream from the gene. To investigate whether disruptions in these genes is causal, we pollinated std1 plants with wildtype pollen and genotyped F2 segregants for insertions in these four genes. Standard T-DNA genotyping was conducted for each set of plants (Figure S2). An analysis of two of the more extreme class 3 segregants and two intermediate phenotype plants (class 2 ) is shown in Table 2. The two class 3 extreme phenotype plants carried wildtype alleles for At3g47580 and At3g03460, eliminating these genes as being causal. Similarly, one of the two plants was wildtype for At4g16490, eliminating it as a candidate. The two class 2 plants were similar in that they were both mutant for At3g21790. However, some of the other intermediate phenotype plants were heterozygous for the insertion, discounting the involvement of At3g21790 (Figure S2). Moreover, it has been reported that insertions into the gene have no obvious phenotype (Dong et al., 2014), nor have any phenotypic defects been reported for insertions in the other three genes (At4g03460: Yu et al., 2020; others inferred from no reported phenotypes on TAIR). Thus, we found no apparent linkage between the std1 mutant and insertions near the four genes. Because of the poor 
fecundity or possible lethality issues with std1, we eventually lost the line, but a subsequent transformation experiment gave rise to a phenotypically identical mutant that we termed std2. TAIL-PCR on std2 DNA identified many similar instances of T-DNA rearrangements, LB/RB tandem repeats and LB read throughs, but also identified At3g03890 as having an insertion within the coding sequence (Table 3 ). This uncharacterized gene is predicted to encode a heme oxygenase. We examined the T-DNA status of At3g03890 in segregants of std2, and found that some mutant plants did not contain T-DNA in this gene, suggesting that disruption of At3g03890 is not causal (Figure S2). Thus, neither of the two independently isolated std mutants seems to possess insertions in common and none of the insertion sites identified by TAIL-PCR faithfully segregated with the mutant phenotype. Because many of the TAIL-PCR sequences were T-DNA repeats and rearrangements, this led us to re-examine the transforming construct and the expression of genes around the HOP2 locus.

\section{The HOP2 locus is genetically dense}

The HOP2pro>HOP2::eGFP reporter construct we used contained a long 5' region (4kbp) which contains the neighboring gene in the opposite orientation. Only 660bp separates the start codon of this gene, At1g13320, encoding a regulatory subunit of protein phosphatase $2 \mathrm{~A}$ (PP2A3), and the start codon of HOP2 (Figure 2). At the 3' end of the reporter gene construct there is a potential overlap in the 3' regulatory region of a gene in the opposing orientation, At1g13340, encoding ISTL6, which may play a role in regulating multivesicular body formation (Buono et al, 2016). Thus, the presence of parts of these neighboring genes in the transforming construct led us to hypothesize that the T-DNA copy number and/or the sites of insertion may lead to misexpression of any or all of the three genes. We therefore examined the expression of these genes by qRT-PCR (Figure 3). Inflorescence RNA was prepared from Ler and std2 plants, and qRT-PCR conducted using control primers for the SAND (At2g28390) gene (Czechowski et al., 2005). We found that HOP2 mRNA levels were over 40 fold higher in std2 than $\operatorname{Ler}\left(2^{\Delta \Delta C T}=5.3\right)$, but the levels of PP2A3 and ISTL6 transcripts were also slightly elevated (3 fold and 2.3 fold, respectively).

\section{Overexpression of HOP2 leads to defects in growth and development}

It is conceivable that slight alterations in the expression of PP2A3 and/or ISTL6 could be responsible for the std phenotype. To more specifically investigate this issue and to determine if HOP2 overexpression is causal, we generated a dexamethasone inducible construct of HOP2 that has no known PP2A regulatory sequence and ends before the 3' end of the HOP2 gene, well before any overlap with the converging ISTL6 transcription unit. The construct also encodes an HA tag at the 3' end. We conducted several experiments to investigate the effect of overexpression of HOP2 on growth and development. First, DEX>HOP::HA (LC842) plants were grown together with wildtype and presented no obvious differences in development when grown on MS medium (Figure 4). However, after transferring seedlings grown on MS medium to medium containing $1 \mu \mathrm{M}$ DEX, DEX>HOP::HA plants remained small and eventually became necrotic and died. Similarly, in soil grown plants, after several foliar applications of DEX to inflorescences, growth of DEX>HOP2::HA plants was compromised (Figure S3) and plants exhibited phyllotaxy defects and reduced fecundity (Figure 5). 
Lastly, we conducted qRT-PCR on seedlings that had been grown on MS media, and then transferred to new MS plates or plates containing 1uM DEX. After 3 days of growth, RNA was prepared and qRT-PCR conducted. We observed that HOP2 was overexpressed by $>8200$ fold $\left(2^{\Delta \Delta C T}=13\right)$, whereas there was little change in PP2A3 or ISTL6 levels (Figure $5 \mathrm{~d}$ ). In addition, we measured the expression of two other PP2A family members, PP2A2 and RCN1, which were largely unchanged. Taken together with the phenotypic changes induced by DEX that mimic std mutants, these experiments point to elevated levels of HOP2 as causing dramatic changes in growth and development.

\section{Discussion}

Although the basic body plan of std mutants is maintained, many aspects of vegetative and reproductive development are affected. Our TAIL-PCR experiments revealed T-DNA insertions near several genes, but these insertions did not faithfully segregate with the std mutant phenotype. For three of the five genes, literature reports suggest that there are no obvious phenotypes from T-DNA insertions (At3g21790, Dong et al., 2014; At4g16490, Luhua et al., 2013; At4g34060, Yu et al., 2020), and no phenotypes have been reported for a variety of insertions in the other two genes. These factors led us to further dissect the HOP2 region, where PP2AA3 and ISTL6 genes partially overlap HOP2. Our qRT-PCR and DEX-inducible HOP2 experiments strongly suggest that misexpression of neither PP2AA3 nor ISTL6 is responsible for the std phenotypes, supporting the conclusion that HOP2 overexpression is causal.

Despite the negative evidence for alterations in PP2A expression as causal, we were intrigued by phenotypes of PP2AA higher order mutants, which are strikingly similar to those of std mutants. In particular, rcn1/pp2a2 and rcn1/pp2a3 double mutants both compromise plant height and fecundity (Zhou et al., 2004). In addition, the extreme class 3 std segregants are phenotypically very similar to the fass/tonneau2 (ton2) mutant in that they exhibit defects in stem elongation and floral organ development, and possess thickened inflorescence stems, thick rumpled leaves, and are sterile (Torres-Ruiz and Jurgens, 1994; Fisher et al., 1996; Camilleri et al., 2002). FASS/TON2 is a regulatory B"' subunit of PP2A phosphatases (Spinner et al., 2013), that interacts with PP2A1/RCN in the yeast two-hybrid system (Camerilli et al, 2002). Moreover, TON1, a protein essential for preprophase band formation (Traas et al., 1995; Azimzadeh et al., 2008), is also a part of this complex, and the ton 1 mutant phenotype shares similarities with our severe class 3 mutants. Despite the lack of evidence for misexpression of PP2A and TON genes, at least at the transcriptional level, the striking similarities of higher order PP2A and TON mutants with our std mutants point to a potential link between HOP2 misexpression and PP2A function. Although PP2A phosphatases control many aspects of cellular metabolism, the misshapen organs and phyllotaxy defects are easily understood in the context of defects in cell division mechanisms and alteration of the planes of division.

How else might HOP2 overexpression underpin the std phenotype? In plants, and as a key feature of meiosis, HOP2 plays roles in the pairing of homologous chromosomes, and in promoting interhomolog DNA repair/recombination (Schommer et al., 2003; Vignard et al., 2007; De Muyt et al., 2009; Stronghill, et al., 2010; Uanschou et al. 2013). HOP2 interacts with its partner protein, MND1, to modulate the activity of the RAD51 and DMC1 repair/recombination 
enzymes (Petukhova et al., 2005; Chi et al., 2007; Bugreev et al., 2014; Zhao et al., 2014; Tsubouchi et al., 2020). Interestingly HOP2 alone can act as a recombinase in vitro (Petukhova et al., 2005). As a protein that fosters recombination, it is conceivable that elevated levels of HOP2 result in somatic recombination, perhaps generating unrepaired templates and/or promoting crossing over between nonhomologous chromosomes that results in chromosome fragmentation and subsequent cell death. Another possibility is suggested by yeast two hybrid experiments in which the rice MND1 protein was shown to interact with replication protein $A$ (RPA; Lu et al., 2020). RPA binds to and stabilizes ssDNA intermediates during DNA replication, repair and homologous recombination. In vitro reconstitution experiments show that HOP2 competes with RPA for binding to ssDNA (Chan et al., 2019). Thus, if HOP2 is overexpressed, ssDNA regions that ordinarily would be stabilized by RPA could assume a conformation that is incompatible with the processes of replication, repair and/or recombination, and failure of these processes (e.g. replication fork collapse) would result in DNA rearrangements and possible cell death. Overexpression of other genes that play roles in DNA/chromosome morphology or behavior has been demonstrated to produce vegetative morphological defects as well as fecundity problems. For example, overexpression of the rice TOP6A1 gene, the homolog of Arabidopsis SP011-1, produces a variety of developmental defects (Jain et. al., 2008). Similarly, plants overexpressing CTF7 $\Delta B$, encoding a kinase that acetylates cohesin complexes and is required for DNA repair, mitosis and meiosis, gives rise to cell division defects as well as a broad range of developmental defects, including dwarfism, fasciation, and phyllotaxy defects (Liu and Makaroff, 2015). It was also recently demonstrated that HOP2 interacts with ATF4, a b-ZIP transcription factor that guides the differentiation of osteoblasts in mice (Zhang et al., 2019). In this regard, Kang and coworkers (2015) conducted molecular dynamics modeling studies of crystallized HOP2/MND1 with DNA, and suggested that the complex distorts the recipient dsDNA. This distortion of the DNA helix could alter the dynamics of transcription factor binding and the overexpression of HOP2 may therefore indirectly alter numerous processes essential for development and physiological homeostasis. Future RNA-seq or microarray analyses could determine whether large scale changes in transcription can be correlated with elevated HOP2 levels.

Cells that have suffered lesions due to faulty repair and/or ectopic recombination events may suffer catastrophic cell death (e.g. by chromosome fragmentation), or may be committed to programmed cell death (PCD). In either case, it is likely that intercellular communication networks are affected, which ultimately would alter hormone homeostasis. In this regard, the release of tryptophan from dying cells is proposed to drive the production of auxin in neighboring cells (Sheldrake and Rupert, 2021), and PCD of root cap cells influences auxin levels and the commitment of adjacent cells into lateral root primordia (Xuan et al., 2016). Some std phenotypes are consistent with altered auxin levels and crosstalk between hormonal biosynthesis and response pathways likely initiate a cascade of hormonal adjustments. For example, the defects in gynoecium development we observed for the std mutants are reminiscent of the phenotypes of well-known mutants such as ettin, crabs claw, spatula, and hecate, whose defects are influenced by and/or influence hormone metabolism (reviewed by Marsch-Martinez and de Folter, 2016). In the future, cytological examination of std mutants and direct hormone measurements would allow this hypothesis to be tested. 


\section{Acknowledgements}

We appreciate the advice on this project and comments on the manuscript by Dr. Clare Hasenkampf (CAH). The authors are grateful to Bruno Chue, Celine Anton, and Ellie Kubisz for their technical assistance. This work was supported by a grant from the Natural Sciences and Engineering Research Council of Canada (NSERC) to CAH and CDR (RGPGP-2015-00071). MK was supported by an NSERC summer fellowship.

\section{References}

Azimzadeh, J., Nacry, P., Christodoulidou, A., Drevensek, S., Camilleri, C., Amiour, N., Parcy, F., Pastuglia, M. and Bouchez, D. (2008) Arabidopsis TONNEAU1 proteins are essential for preprophase band formation and interact with centrin. Plant Cell, 20, 2146-2159.

Bugreev, D.V., Huang, F., Mazina, O.M., Pezza, R.J., Voloshin, O.N., Camerini-Otero, R.D. and Mazin, A.V. (2014) HOP2-MND1 modulates RAD51 binding to nucleotides and DNA. Nature Communications, 5, 10.

Buono, R.A., Paez-Valencia, J., Miller, N.D., Goodman, K., Spitzer, C., Spalding, E.P. and Otegui, M.S. (2016) Role of SKD1 Regulators LIP5 and IST1-LIKE1 in Endosomal Sorting and Plant Development. Plant Physiology, 171, 251-264.

Camilleri, C., Azimzadeh, J., Pastuglia, M., Bellini, C., Grandjean, O. and Bouchez, D. (2002) The Arabidopsis TONNEAU2 gene encodes a putative novel protein phosphatase 2A regulatory subunit essential for the control of the cortical cytoskeleton. Plant Cell, 14, 833-845.

Chan, Y.L., Zhang, A.N., Weissman, B.P. and Bishop, D.K. (2019) RPA resolves conflicting activities of accessory proteins during reconstitution of Dmc1-mediated meiotic recombination. Nucleic Acids Research, 47, 747-761.

Chi, P., San Filippo, J., Sehorn, M.G., Petukhova, G.V. and Sung, P. (2007) Bipartite stimulatory action of the Hop2-Mnd1 complex on the Rad51 recombinase. Genes \& Development, 21, 1747-1757.

Crickard, J. B., and Greene, E. C. (2018). The biochemistry of early meiotic recombination intermediates. Cell Cycle, 17, 2520-2530.

Czechowski, T., Stitt, M., Altmann, T., Udvardi, M.K. and Scheible, W.R. (2005) Genome-wide identification and testing of superior reference genes for transcript normalization in Arabidopsis. Plant Physiology, 139, 5-17.

Da Ines, O. and White, C.I. (2015) Centromere Associations in Meiotic Chromosome Pairing. In Annual Review of Genetics, Vol 49 (Bassler, B.L. ed, pp. 95-114.

De Buck, S., Jacobs, A., Van Montagu, M. and Depicker, A. (1999) The DNA sequences of T-DNA junctions suggest that complex T-DNA loci are formed by a recombination process resembling T-DNA integration. Plant Journal, 20, 295-304.

De Muyt, A., Pereira, L., Vezon, D., Chelysheva, L., Gendrot, G., Chambon, A., Laine-Choinard, S., Pelletier, G., Mercier, R., Nogue, F. and Grelon, M. (2009) A High Throughput Genetic Screen Identifies New Early Meiotic Recombination Functions in Arabidopsis thaliana. Plos Genetics, 5, 14. 
DeNeve, M., DeBuck, S., Jacobs, A., VanMontagu, M. and Depicker, A. (1997) T-DNA integration patterns in co-transformed plant cells suggest that T-DNA repeats originate from co-integration of separate T-DNAs. Plant Journal, 11, 15-29.

Dong, T., Xu, Z.Y., Park, Y., Kim, D.H., Lee, Y. and Hwang, I. (2014) Abscisic acid uridine diphosphate glucosyltransferases play a crucial role in abscisic acid homeostasis in Arabidopsis. Plant Physiology, 165, 277-289.

Douglas, S.J., Chuck, G., Dengler, R.E., Pelecanda, L. and Riggs, C.D. (2002) KNAT1 and ERECTA regulate inflorescence architecture in Arabidopsis. Plant Cell, 14, 547-558.

Douglas, S.J., Li, B.H., Kliebenstein, D.J., Nambara, E. and Riggs, C.D. (2017) A novel filamentous flower mutant suppresses brevipedicellus developmental defects and modulates glucosinolate and auxin levels. Plos One, 12. 10.1371/journal.pone.0177045

Farahani-Tafreshi, Y., Wei, C., Gan, P., Daradur, J., Riggs, C.D., and Hasenkampf, C.A. (2021). The Arabidopsis HOP2 gene has a role in preventing illegitimate exchanges between nonhomologous chromosomes. bioRxiv, 2021.2008.2004.455073. doi:10.1101/2021.08.04.455073.

Fisher, R.H., Barton, M.K., Cohen, J.D. and Cooke, T.J. (1996) Hormonal studies of fass, an Arabidopsis mutant that is altered in organ elongation. Plant Physiology, 110, 1109-1121.

Greene, E.C. (2016) DNA Sequence Alignment during Homologous Recombination. Journal of Biological Chemistry, 291, 11572-11580.

Hurel, A., Phillips, D., Vrielynck, N., Mézard, C., Grelon, M. and Christophorou, N. (2018) A cytological approach to studying meiotic recombination and chromosome dynamics in Arabidopsis thaliana male meiocytes in three dimensions. Plant Journal, 95, 385-396.

Jain, M., Tyagi, A.K. and Khurana, J.P. (2008) Constitutive expression of a meiotic recombination protein gene homolog, OsTOP6A1, from rice confers abiotic stress tolerance in transgenic Arabidopsis plants. Plant Cell Reports, 27, 767-778.

Kang, H.A., Shin, H.C., Kalantzi, A.S., Toseland, C.P., Kim, H.M., Gruber, S., Dal Peraro, M. and Oh, B.H. (2015) Crystal structure of Hop2-Mnd1 and mechanistic insights into its role in meiotic recombination. Nucleic Acids Research, 43, 3841-3856.

Kerzendorfer, C., Vignard, J., Pedrosa-Harand, A., Siwiec, T., Akimcheva, S., Jolivet, S., Sablowski, R., Armstrong, S., Schweizer, D., Mercier, R. and Schlogelhofer, P. (2006) The Arabidopsis thaliana MND1 homologue plays a key role in meiotic homologous pairing, synapsis and recombination. Journal of Cell Science, 119, 2486-2496.

Leu, J.Y., Chua, P.R. and Roeder, G.S. (1998) The meiosis-specific hop2 protein of S-cerevisiae ensures synapsis between homologous chromosomes. Cell, 94, 375-386.

Liu, D.S. and Makaroff, C.A. (2015) Overexpression of a truncated CTF7 construct leads to pleiotropic defects in reproduction and vegetative growth in Arabidopsis. Bmc Plant Biology, 15, 16.

Lu, J.Y., Wang, C.L., Wang, H.Y., Zheng, H., Bai, W.T., Lei, D.K., Tian, Y.L., Xiao, Y.J., You, S.M., Wang, Q.M., Yu, X.W., Liu, S.J., Liu, X., Chen, L.M., Jang, L., Wang, C.M., Zhao, Z.G. and Wan, J.M. (2020) OsMFS1/OsHOP2 Complex Participates in Rice Male and Female Development. Frontiers in Plant Science, 11.

Luhua, S., Hegie, A., Suzuki, N., Shulaev, E., Luo, X., Cenariu, D., Ma, V., Kao, S., Lim, J., Gunay, M.B., Oosumi, T., Lee, S.C., Harper, J., Cushman, J., Gollery, M., Girke, T., Bailey-Serres, J., Stevenson, R.A., Zhu, J.-K. and Mittler, R. (2013) Linking genes of unknown function with 
abiotic stress responses by high-throughput phenotype screening. Physiologia Plantarum, 148, 322-333.

Marsch-Martinez, N. and de Folter, S. (2016) Hormonal control of the development of the gynoecium. Current Opinion in Plant Biology, 29, 104-114.

Neale, M.J. and Keeney, S. (2006) Clarifying the mechanics of DNA strand exchange in meiotic recombination. Nature, 442, 153-158.

Panoli, A.P., Ravi, M., Sebastian, J., Nishal, B., Reddy, T.V., Marimuthu, M.P.A., Subbiah, V., Vijaybhaskar, V. and Siddiqi, I. (2006) AtMND1 is required for homologous pairing during meiosis in Arabidopsis. Bmc Molecular Biology, 7. doi:10.1186/1471-2199-7-24

Petukhova, G.V., Pezza, R.J., Vanevski, F., Ploquin, M., Masson, J.Y. and Camerini-Otero, R.D. (2005) The Hop2 and Mnd1 proteins act in concert with Rad51 and Dmc1 in meiotic recombination. Nature Structural \& Molecular Biology, 12, 449-453.

Petukhova, G.V., Romanienko, P.J. and Camerini-Otero, R.D. (2003) The Hop2 protein has a direct role in promoting interhomolog interactions during mouse meiosis. Developmental Cell, 5, 927936.

Ploquin, M., Petukhova, G. V., Morneau, D., Dery, U., Bransi, A., Stasiak, A., .. Masson, J. Y. (2007). Stimulation of fission yeast and mouse Hop2-Mnd1 of the Dmc1 and Rad51 recombinases. Nucleic Acids Research, 35, 2719-2733.

Schommer, C., Beven, A., Lawrenson, T., Shaw, P. and Sablowski, R. (2003) AHP2 is required for bivalent formation and for segregation of homologous chromosomes in Arabidopsis meiosis. Plant Journal, 36, 1-11.

Sepsi, A. and Schwarzacher, T. (2020) Chromosome-nuclear envelope tethering - a process that orchestrates homologue pairing during plant meiosis? Journal of Cell Science, 133.

Sessions, A., Burke, E., Presting, G., Aux, G., McElver, J., Patton, D., Dietrich, B., Ho, P., Bacwaden, J., Ko, C., Clarke, J.D., Cotton, D., Bullis, D., Snell, J., Miguel, T., Hutchison, D., Kimmerly, B., Mitzel, T., Katagiri, F., Glazebrook, J., Law, M. and Goff, S.A. (2002) A high-throughput Arabidopsis reverse genetics system. Plant Cell, 14, 2985-2994.

Sheldrake, A.R. (2021) The production of auxin by dying cells. Journal of Experimental Botany, $\mathbf{7 2}$, 2288-2300.

Shi, W.Q., Tang, D., Shen, Y., Xue, Z.H., Zhang, F.F., Zhang, C., Ren, L.J., Liu, C.Z., Du, G.J., Li, Y.F., Yan, C.J. and Cheng, Z.K. (2019) OsHOP2 regulates the maturation of crossovers by promoting homologous pairing and synapsis in rice meiosis. New Phytologist, 222, 805-819.

Spinner, L., Gadeyne, A., Belcram, K., Goussot, M., Moison, M., Duroc, Y., Eeckhout, D., De Winne, N., Schaefer, E., Van De Slijke, E., Persiau, G., Witters, E., Gevaert, K., De Jaeger, G., Bouchez, D., Van Damme, D. and Pastuglia, M. (2013) A protein phosphatase 2A complex spatially controls plant cell division. Nature Communications, 4, 1863.

Stronghill, P., Pathan, N., Ha, H., Supijono, E. and Hasenkampf, C. (2010) Ahp2 (Hop2) function in Arabidopsis thaliana (Ler) is required for stabilization of close alignment and synaptonemal complex formation except for the two short arms that contain nucleolus organizer regions. Chromosoma, 119, 443-458.

Tian, M., Agreiter, C. and Loidl, J. (2020) Spatial constraints on chromosomes are instrumental to meiotic pairing. Journal of Cell Science, 133.

Torres-Ruiz, R.A. and Jurgens, G. (1994) Mutations in the FASS gene uncouple pattern formation and morphogenesis in Arabidopsis development. Development, 120, 2967-2978. 
Traas, J., Bellini, C., Nacry, P., Kronenberger, J., Bouchez, D. and Caboche, M. (1995) Normal differentiation patterns in plants lacking microtubular preprophase bands. Nature, 375, 676-677.

Tsubouchi, H. and Roeder, G.S. (2003) The Importance of Genetic Recombination for Fidelity of Chromosome Pairing in Meiosis. Developmental Cell, 5, 915-925.

Tsubouchi, H., Argunhan, B., Ito, K., Takahashi, M., and Iwasaki, H. (2020). Two auxiliary factors promote Dmc1-driven DNA strand exchange via stepwise mechanisms. Proceedings of the National Academy of Sciences of the United States of America, 117, 12062-12070.

Uanschou, C., Ronceret, A., Von Harder, M., De Muyt, A., Vezon, D., Pereira, L., Chelysheva, L., Kobayashi, W., Kurumizaka, H., Schlogelhofer, P. and Grelon, M. (2013) Sufficient Amounts of Functional HOP2/MND1 Complex Promote Interhomolog DNA Repair but Are Dispensable for Intersister DNA Repair during Meiosis in Arabidopsis. Plant Cell, 25, 4924-4940.

Unhavaithaya, Y. and Orr-Weaver, T.L. (2013) Centromere proteins CENP-C and CAL1 functionally interact in meiosis for centromere clustering, pairing, and chromosome segregation. Proc. Natl. Acad. Sci. U. S. A., 110, 19878-19883.

Vignard, J., Siwiec, T., Chelysheva, L., Vrielynck, N., Gonord, F., Armstrong, S.J., Schlogelhofer, P. and Mercier, R. (2007) The interplay of RecA-related proteins and the MND1-HOP2 complex during meiosis in Arabidopsis thaliana. Plos Genetics, 3, 1894-1906.

Wei, S., Xi, Y.Z., Song, D.P., Wei, H., Gruber, M.Y., Gao, M.J., Parkin, I., Kachatourians, G. and Hannoufa, A. (2015) Quantitative and structural analyses of T-DNA tandem repeats in transgenic Arabidopsis SK mutant lines. Plant Cell Tissue and Organ Culture, 123, 183-192.

Xuan, W., Band, L.R., Kumpf, R.P., Van Damme, D., Parizot, B., De Rop, G., Opdenacker, D., Moller, B.K., Skorzinski, N., Njo, M.F., De Rybel, B., Audenaert, D., Nowack, M.K., Vanneste, S. and Beeckman, T. (2016) Cyclic programmed cell death stimulates hormone signaling and root development in Arabidopsis. Science, 351, 384-387.

Yu, Y., Liang, Z., Song, X., Fu, W., Xu, J., Lei, Y., Yuan, L., Ruan, J., Chen, C., Fu, W., Cui, Y., Huang, S. and Li, C. (2020) BRAHMA-interacting proteins BRIP1 and BRIP2 are core subunits of Arabidopsis SWI/SNF complexes. Nature Plants, 6, 996-1007.

Zhang, Y., Lin, T., Lian, N., Tao, H., Li, C., Li, L. and Yang, X. (2019) Hop2 Interacts with ATF4 to Promote Osteoblast Differentiation. Journal of Bone and Mineral Research, 34, 2287-2300.

Zhao, W.X., Saro, D., Hammel, M., Kwon, Y., Xu, Y.Y., Rambo, R.P., Williams, G.J., Chi, P., Lu, L., Pezza, R.J., Camerini-Otero, R.D., Tainer, J.A., Wang, H.W. and Sung, P. (2014) Mechanistic insights into the role of Hop2-Mnd1 in meiotic homologous DNA pairing. Nucleic Acids Research, 42, 906-917.

Zhou, H.W., Nussbaumer, C., Chao, Y. and DeLong, A. (2004) Disparate roles for the regulatory A subunit isoforms in Arabidopsis protein phosphatase 2A. Plant Cell, 16, 709-722. 
Table 1: TAIL-PCR of std1 reveals multiple gene insertions and complex integration events

\begin{tabular}{|c|c|}
\hline $\begin{array}{l}\text { Sequence } \\
\text { count }\end{array}$ & Identity/annotation \\
\hline 13 & Sequence reads through LB into vector DNA \\
\hline 10 & $\begin{array}{l}\text { Insertion upstream from At4g16490 } \\
\text { • encodes an Armadillo repeat protein }\end{array}$ \\
\hline 4 & T-DNA tandem repeat \\
\hline 3 & Complex T-DNA rearrangement or PCR artifact \\
\hline 3 & $\begin{array}{l}\text { Insertion upstream from At3g21790 } \\
\quad \quad \text { encodes UDP-glucosyltransferase 71B7 }\end{array}$ \\
\hline 3 & $\begin{array}{l}\text { Insertion upstream from At3g47580 } \\
\text { • encodes an LRR protein kinase family member }\end{array}$ \\
\hline 2 & $\begin{array}{l}\text { Insertion downstream from At3g03460 } \\
\text { • encodes an ankyrin repeat family protein }\end{array}$ \\
\hline
\end{tabular}


Table 2: Segregation of T-DNA insertions in four target genes in std1 segregants

\begin{tabular}{|c|l|c|c|c|c|}
\hline $\begin{array}{c}\text { Plant } \\
\text { Number }\end{array}$ & $\begin{array}{l}\text { Phenotypic } \\
\text { summary }\end{array}$ & $\begin{array}{c}\text { At4g16490 } \\
\text { status }\end{array}$ & $\begin{array}{c}\text { At3g21790 } \\
\text { status }\end{array}$ & $\begin{array}{c}\text { At3g03456 } \\
\text { status }\end{array}$ & $\begin{array}{c}\text { At3g48590 } \\
\text { status }\end{array}$ \\
\hline 1 & $\begin{array}{l}\text { Short plants with } \\
\text { short, thick stems, } \\
\text { thick and wavy } \\
\text { leaves, altered } \\
\text { phyllotaxy, sterile } \\
\text { (class 3 plants) }\end{array}$ & T-DNA & T-DNA & WT & WT \\
\hline 10 & $\begin{array}{l}\text { Reduced height } \\
\text { plants with } \\
\text { abnormal } \\
\text { phyllotaxy, reduced } \\
\text { fecundity } \\
\text { (class 2 plants })\end{array}$ & T-DNA & T-DNA & WT & WT \\
\hline 14 & T-DNA & WT & WT \\
\hline
\end{tabular}

Table 3: TAIL-PCR of std2 reveals a single gene target and complex T-DNA integration events

\begin{tabular}{|c|l|}
\hline Sequence count & \multicolumn{1}{|c|}{ Identity/annotation } \\
\hline 14 & T-DNA rearrangement/PCR artifact \\
\hline 10 & Tandem repeat T-DNA \\
\hline 7 & Reads through LB into vector DNA \\
\hline 3 & Gene target (At3g03890) \\
\hline 1 & Converging T-DNA \\
\hline
\end{tabular}




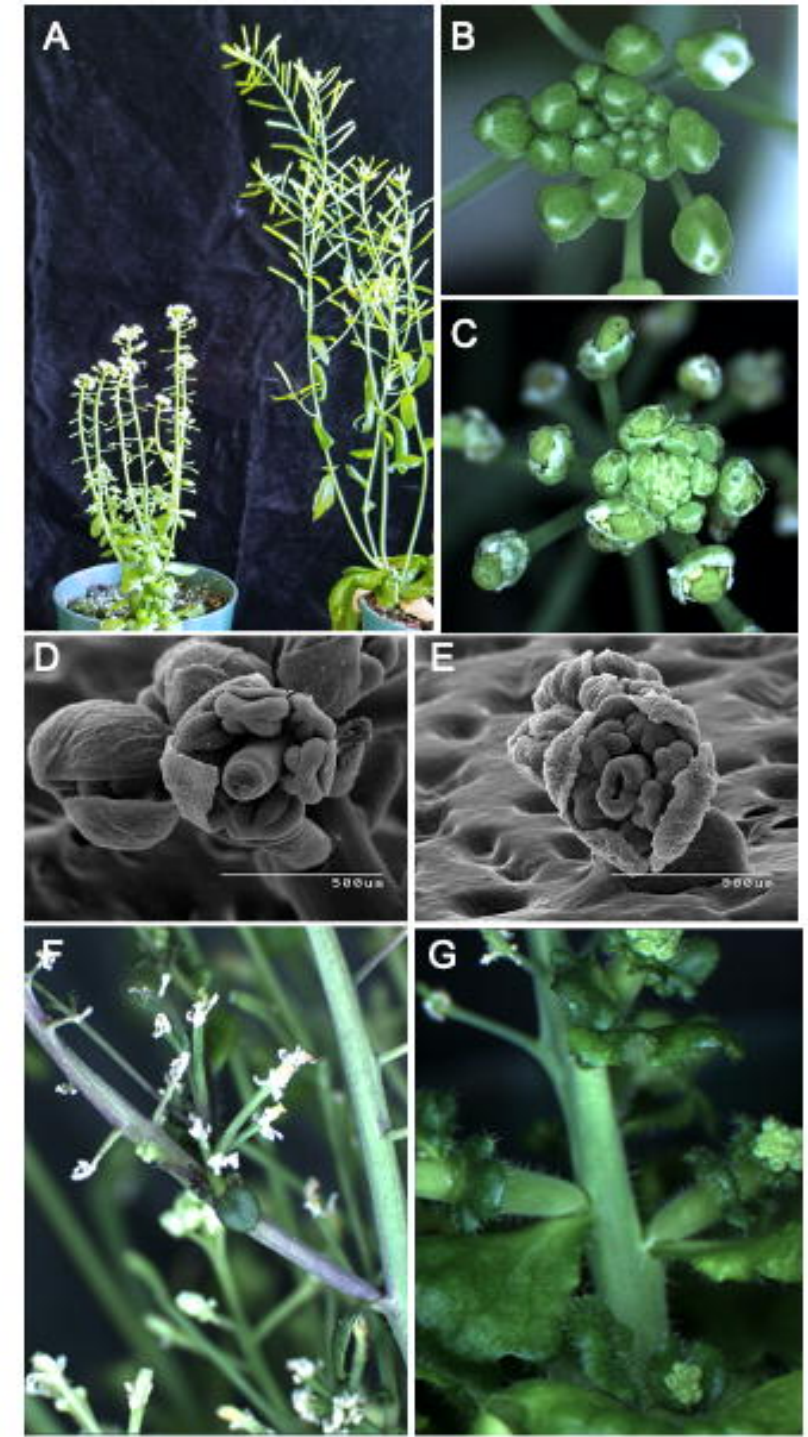

Figure 1: std1 mutant phenotypes. A. An std1 plant on the left and wildtype (Ler) plant on the right. std1 plant height is compromised and leaves are smaller, rounder and epinastic. B, C. inflorescences of wildtype (B) and std1 (C),

illustrating floral organ growth defects resulting in flattened and open buds. D, E. SEM photomicrographs illustrating sepal and pistil growth defects in wildtype (D) and std 1 (E). F. Phyllotaxy defects, reduced fecundity and elevated anthocyanin production in std1. G. Extreme phenotypes of std segregants that include thick and ruffled leaves, fasciated stems, and phyllotaxy and floral defects 


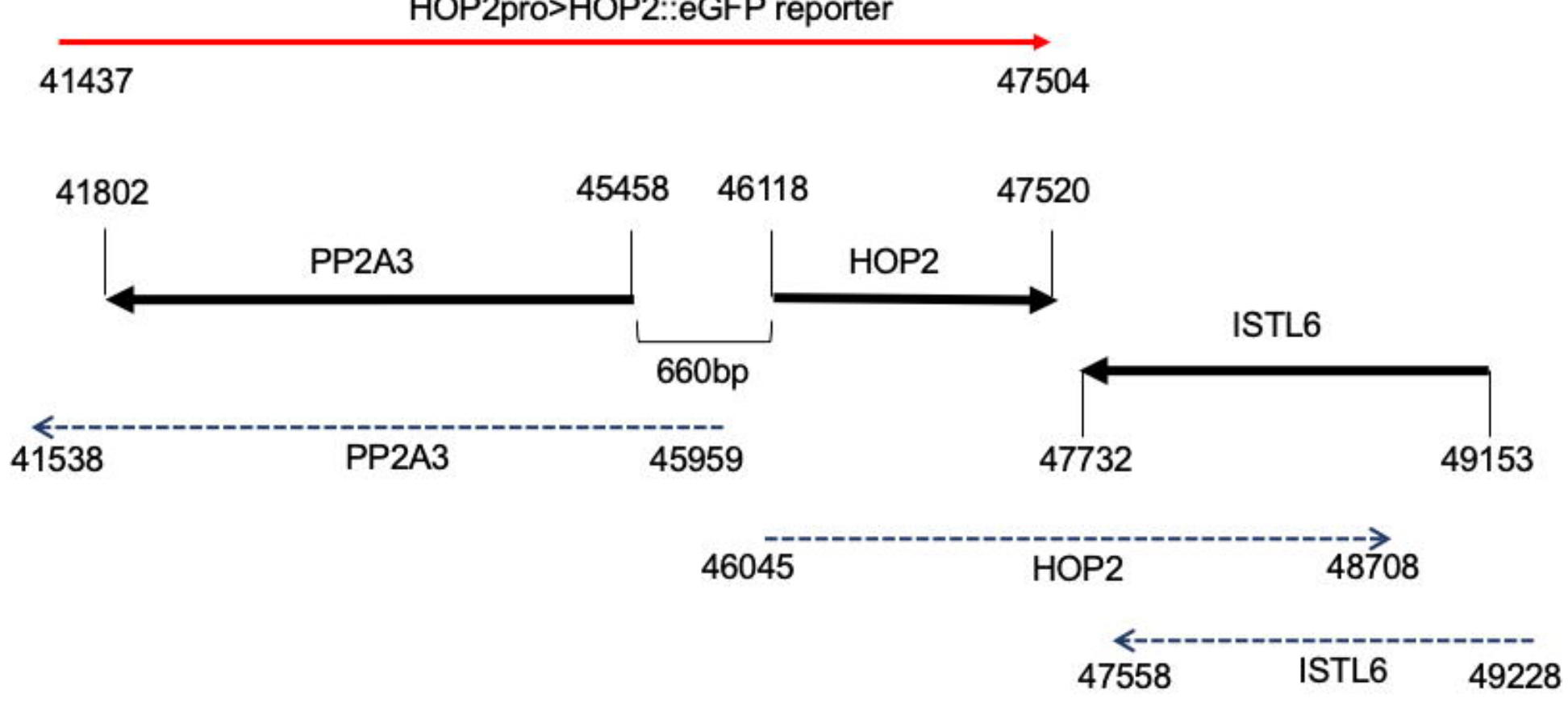

Figure 2: The HOP2 locus is genetically dense. A schematic of three neighboring and partially overlapping genes: HOP2, PP2A3 and ISTL6, is shown. Numbers refer to the BAC T6J4 coordinates of the start and stop codons of the three genes. The region matching the T-DNA used for transformation is shown in red. Transcript maps are shown by hatched lines with inclusive coordinates. 


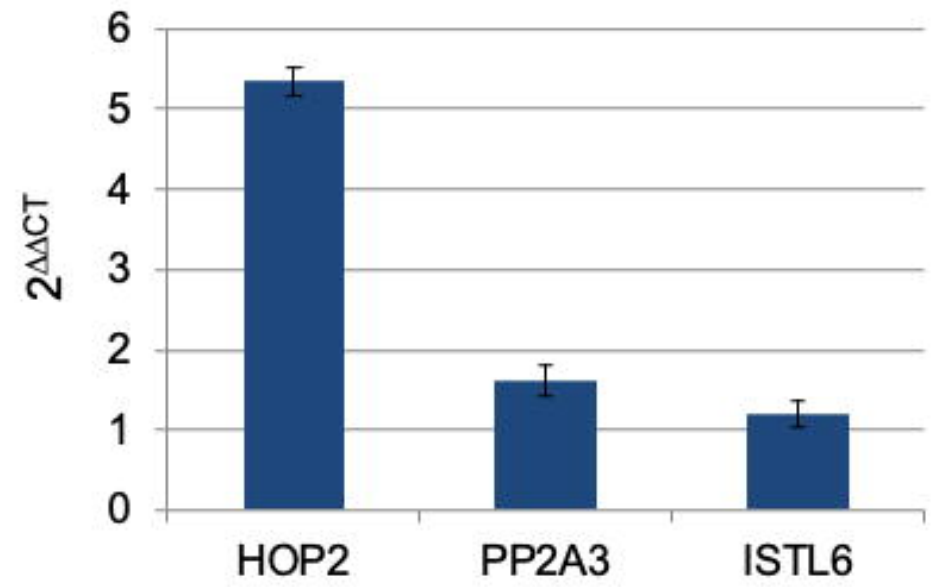

Figure 3: Transcript levels of HOP2, PP2A3 and ISTL6 in std2 inflorescences. Triplicate samples for Ler and std1 were subjected to qRT-PCR with primer sets for the three genes. SAND1 was employed as a control primer and $2^{\triangle \triangle C T}$ values were determined. Error bars represent standard error of the mean. 


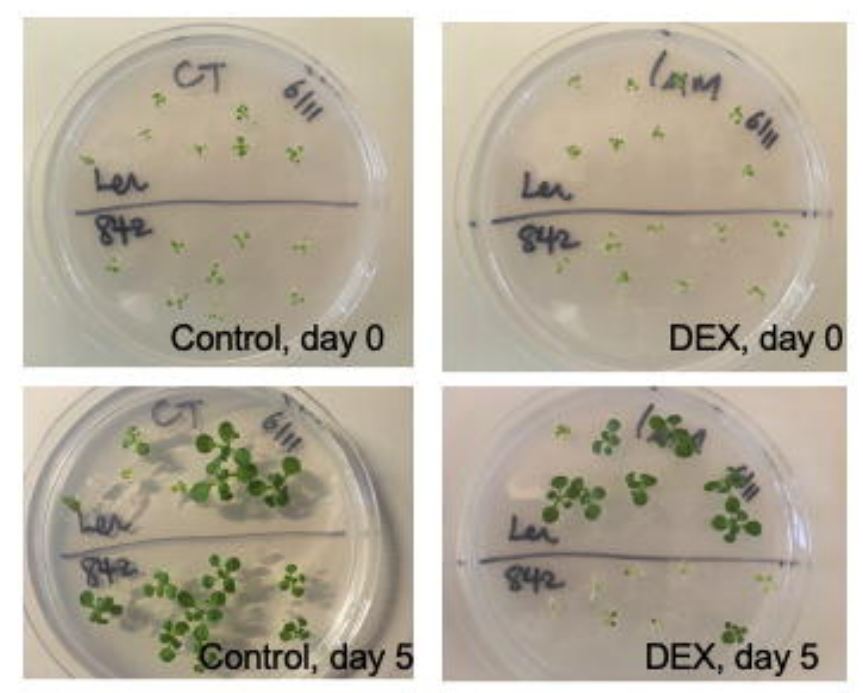

Figure 4: DEX-induced HOP2 compromises plant growth. Seeds of Ler, and Ler harboring LC842 (DEX>HOP2::HA) were germinated on MS medium and one week old seedlings were gridded to control (MS) plates, and MS plates containing $1 \mathrm{UM}$ DEX. Plates were

photographed at day 0 (gridding day) and at day 5 after gridding. 
